\title{
One-Pot Synthesis of Nanoscale Zero-Valent Iron Immobilized with Granular Activated
} Carbon

Mines, Paul Douglas; Andersen, Henrik Rasmus; Hwang, Yuhoon

Published in:

International Journal of Environmental Research

Link to article, DOI:

10.1007/s41742-018-0132-9

Publication date:

2018

Document Version

Peer reviewed version

Link back to DTU Orbit

Citation $(A P A)$ :

Mines, P. D., Andersen, H. R., \& Hwang, Y. (2018). One-Pot Synthesis of Nanoscale Zero-Valent Iron

Immobilized with Granular Activated Carbon. International Journal of Environmental Research, 12(5), 725-734. https://doi.org/10.1007/s41742-018-0132-9

\section{General rights}

Copyright and moral rights for the publications made accessible in the public portal are retained by the authors and/or other copyright owners and it is a condition of accessing publications that users recognise and abide by the legal requirements associated with these rights.

- Users may download and print one copy of any publication from the public portal for the purpose of private study or research.

- You may not further distribute the material or use it for any profit-making activity or commercial gain

- You may freely distribute the URL identifying the publication in the public portal 


\title{
One-pot synthesis of nanoscale zero-valent iron immobilized with granular activated carbon
}

\author{
Paul D. Mines ${ }^{1}$, Henrik R. Andersen², and Yuhoon Hwang ${ }^{3 *}$ \\ ${ }^{1}$ Department of Micro- and Nanotechnology, Technical University of Denmark, DK-2800 Kongens Lyngby, Denmark \\ ${ }^{2}$ Department of Environmental Engineering, Technical University of Denmark, DK-2800 Kongens Lyngby, Denmark \\ ${ }^{3}$ Department of Environmental Engineering, Seoul National University of Science and Technology, Seoul 01811, Korea
}

\begin{abstract}
Activated carbon has widely been used to adsorb and remove various pollutants, but it is not an adequate treatment solution for degrading pollutants; rather, it merely transforms the pollutants from a liquid-phase to a solid-phase bound in the carbon matrix. In this study, we have investigated the immobilization of nanoscale zero-valent iron (nZVI) on granular activated carbon (GAC) for the purpose of providing redox reactivity towards water pollutants. Two representative processes for nZVI immobilization on granular activated carbon (GAC/Fe) were evaluated, and concluded by the suggestion of optimized conditions for synthesizing GAC/Fe composites. Both total iron content and $\mathrm{Fe}^{0}$ content can be significantly influenced by the preparation process; therefore, it was important to avoid oxidation during preparation, in order to achieve the highest possible reduction capacity. The optimal condition for producing reactive GAC/Fe was determined to be immersing GAC in a $\mathrm{Fe}^{2+}$ solution for $24 \mathrm{~h}$, followed by the reduction of $\mathrm{Fe}^{2+}$ to $\mathrm{Fe}^{0}$ without an intermediate drying step. The reactivity of prepared GAC/Fe was tested by evaluating nitrate reduction; additionally, the effect of acid addition was investigated. A colorimetric assay was applied to quantify the reaction products, whereupon the effectiveness of the colorimetric assay was well verified. Ultimately, the prepared GAC/Fe composite demonstrated a synergistic effect between the adsorption capability of the GAC and the degradation capability of the nZVI, which make this composite a very effective material for environmental remediation.
\end{abstract}

\section{Keywords}

Nanoscale zero-valent iron, granular activated carbon, iron impregnation, immobilization, oxidation-reduction

\footnotetext{
* Corresponding authors

E-mail: yhhwang@seoultech.ac.kr, Tel: +82-2-970-6626, Fax: +82-2-971-5776
} 


\section{INTRODUCTION}

As international water scarcity problems have grown and the demand for stable water supply has increased, new, effective, and applicable water treatment methods have actively been studied. Various materials for effective water treatment have been developed and introduced in various fields, ranging from the development of novel materials, such as nanomaterials (Savage and Diallo 2005) and biomimetic membranes (Tang et al. 2013), to the modification of materials commonly used in existing water treatment processes like activated carbon (Rivera-Utrilla et al. 2011; Mines et al. 2017). To date, activated carbon has been widely used to adsorb and remove various pollutants, such as pesticides (Hameed et al. 2009), heavy metals (Kobya et al. 2005), and pharmaceuticals (Grover et al. 2011) in the water treatment process. It has the advantage of adsorption potential for various pollutants at a very low cost; however, it also has a disadvantage in that it is not a capable treatment mechanism for degrading pollutants, rather it merely transforms the pollutants from a liquid-phase to a solid-phase bound in the carbon matrix.

Research has been conducted to immobilize reactive nano-metal particles on the surface of and in the pores of activated carbon, in order to overcome the limitations of the pollutant removal mechanism of activated carbon and to provide reactivity that consequently degrades pollutants. For example, immobilization of titanium dioxide $\left(\mathrm{TiO}_{2}\right)$ with activated carbon allows for photocatalytic degradation of compounds (Subramani et al. 2007) and silver nanoparticle (Ag) immobilization has been applied to enhance activated carbon with antimicrobial properties (Yoon et al. 2008).

Nanoscale zero-valent iron (nZVI) is known to be capable of effectively treating materials such as chlorinated organic compounds, nitrate, and nitrobenzene through redox reactions (Crane and Scott 2012). It has a high reactivity due to its small size and high specific surface area, which can then drastically shorten the treatment period. On the other hand, due to its small size (i.e. $<100 \mathrm{~nm}$ diameter), it is difficult to recover from the treated effluent; and thus, it has not been widely applied due to concerns of subsequent leakage into the final produced water. In order to overcome the limitations of such applications, studies have been actively conducted to immobilize zero-valent iron nanoparticles (nZVI) on a carrier such as granular activated carbon (GAC) (Zhu et al. 2009; Mines et al. 2018), alginate (Kim et al. 2010), or membranes (Liu et al. 2014). Among them, the immobilization technique using activated carbon as a carrier has been actively studied because of its low cost, as well as its high applicability and versatility in water treatment operations.

Several immobilization methods have been proposed through various studies, and it has been reported that nanoscale 
zero-valent iron immobilized granular activated carbon (GAC/nZVI) with different properties can be produced depending on the particular synthesis conditions. Typical synthesis methods include immersing activated carbon in a high-concentration iron nitrate solution, volatilizing the anions of the iron solution at high temperatures to physicochemically immobilize the iron (Choi et al. 2008), and immersing the GAC in a low-concentration iron solution at room temperature to facilitate the chemical attachment of iron ions (Tseng et al. 2011).

However, there is a lack of systematic study on how the properties of composites are changed according to each synthesis method and the reasons behind these changes. Therefore, in this study, we investigated the effect of the synthesis pathway on the properties of GAC/Fe composites produced, in terms of the amount of immobilized reactive iron. Moreover, in order to understand the reduction efficiency and the reaction mechanism, the final synthesized GAC/Fe composites were tested for reactivity by assessing their ability to degrade nitrate. Finally, our previously developed colorimetric assay to quantify the reducing reactivity of nZVI (Hwang et al. 2016) has been applied to analyze the produced composites and more completely evaluate their reactivity.

\section{METHODS}

\subsection{Iron attachment on granular activated carbon}

Three different strategies were employed to create different GAC/Fe composites, a wetness impregnation method (GAC/Fe 1) and two different routes using direct $\mathrm{Fe}^{2+}$ attachment by soaking GAC into $\mathrm{Fe}\left(\mathrm{SO}_{4}\right)$ solution (GAC/Fe 2 and GAC/Fe 3). The overall outline of the methods is detailed in Fig. 1.

Fig 1. Overall synthesis procedures for the different GAC/Fe composites.

\subsubsection{Wetness impregnation method}

This synthesis method was partially modified from previously reported methods in existing literature (Choi et al. 2008). Granular activated carbon (GAC, 1240W, Norit ${ }^{\circledR}$ ) used in this study possesses an effective diameter of $0.6-0.7$ mm. First in the composite synthesis, the GAC was washed with deionized water and dried at $60{ }^{\circ} \mathrm{C}$ for $24 \mathrm{~h}$. Then, 10 g of washed GAC were placed in a ceramic crucible and $5 \mathrm{~mL}$ of $11.3 \mathrm{M}$ ferric nitrate $\left(\mathrm{Fe}\left(\mathrm{NO}_{3}\right)_{3} \cdot 9 \mathrm{H}_{2} \mathrm{O}\right)$ solution was added, followed by stirring for $10 \mathrm{~min}$ with a magnetic stirrer. Afterwards, the nitrate anions in the ferric nitrate solution were volatilized using a heating oven. The heating conditions were $1 \mathrm{~h}$ at $150{ }^{\circ} \mathrm{C}$ and 4 hours at $300{ }^{\circ} \mathrm{C}$, the temperature was increased at a rate of $3{ }^{\circ} \mathrm{C}$ per min. Prepared samples were stored in an anaerobic chamber to prevent 
further oxidation. The nZVI/GAC composite synthesized using the above conditions was named GAC/Fe 1 . The overall scheme is presented in Fig. 1.

\subsubsection{Direct $\mathrm{Fe}^{2+}$ attachment by soaking GAC into $\mathrm{Fe}\left(\mathrm{SO}_{4}\right)$ solution}

This synthesis method was partially modified by using the synthesis method presented in the existing literature (Tseng et al. 2011). First, $10 \mathrm{~g}$ of washed GAC was placed in a 3-necked round bottom flask, and $150 \mathrm{~mL}$ of $0.84 \mathrm{M}$ $\mathrm{FeSO}_{4} \cdot 7 \mathrm{H}_{2} \mathrm{O}$ solution was injected, followed by stirring for $24 \mathrm{~h}$. The $\mathrm{pH}$ during $\mathrm{Fe}^{2+}$ adsorption (non-adjusted and adjusted to 7), adsorption time, and concentration were investigated to determine the optimal conditions. The $\mathrm{pH}$ was adjusted by using $1 \mathrm{M} \mathrm{H}_{2} \mathrm{SO}_{4}$ and $\mathrm{NaOH}$ solutions. Nitrogen gas was continuously delivered to the flask, in order to prevent oxidation of $\mathrm{Fe}^{2+}$ ions during stirring. After stirring for $24 \mathrm{~h}$, the solid was separated using a sieve (40 mesh, $0.42 \mathrm{~mm}$ ), washed with deionized water and ethanol (99.9\%), and dried in a vacuum oven at $60{ }^{\circ} \mathrm{C}$ for $4 \mathrm{~h}$. Prepared samples were stored in an anaerobic chamber to prevent further oxidation. The synthesized samples without and with $\mathrm{pH}$ adjustment were named as GAC/Fe 2 and GAC/Fe 3, respectively.

\subsubsection{One-pot synthesis}

In order to investigate the effect of the drying conditions on the synthesis, the samples were reduced to zero-valent iron using $\mathrm{NaBH}_{4}$ immediately after the agitation and washing process without drying. Detailed conditions for reduction are described in section 2.2 below. The obtained samples were named as GAC/Fe 2A and GAC/Fe 3A.

\subsection{Reduction of attached iron to zero-valent state by $\mathrm{NaBH}_{4}$}

The chemical reduction method using $\mathrm{NaBH}_{4}$ was used to reduce iron $\left(\mathrm{Fe}^{2+} / \mathrm{Fe}^{3+}\right)$ attached to GAC to zero-valent iron $\left(\mathrm{Fe}^{0}\right)$. The reaction of iron ions with $\mathrm{NaBH}_{4}$ takes place as shown in the following reaction (Eq. 1) (Hwang et al. 2014).

$$
\left.2 \mathrm{Fe}^{2+}+\mathrm{BH}_{4}^{-}+3 \mathrm{H}_{2} \mathrm{O} \rightarrow 2 \mathrm{Fe}^{0}+\mathrm{H}_{2} \mathrm{BO}_{3}^{-}+4 \mathrm{H}^{+}+2 \mathrm{H}_{2} \text { (Eq. } 1\right)
$$

$10 \mathrm{~g}$ of iron-loaded GAC was placed in a 3-necked round bottom flask and $150 \mathrm{~mL}$ of $1.19 \mathrm{M} \mathrm{NaBH}_{4} \mathrm{Solution}$ was injected at a flow rate of $10 \mathrm{~mL} / \mathrm{min}$ using a metering pump. Nitrogen gas was continuously delivered into the flask to prevent oxidation during the reaction. After the injection was completed, stirring was continued for $2 \mathrm{~h}$ so that the reaction could run to completion. After the reduction was completed, it was washed with deionized water and ethanol 
(99.9\%) and then dried in a vacuum oven at $60{ }^{\circ} \mathrm{C}$ for $4 \mathrm{~h}$. Prepared samples were stored in an anaerobic chamber to prevent further oxidation.

\subsection{Characterization of prepared GAC/nZVI composites}

\subsubsection{Fe(0) content}

An acid elution method was used to measure the total iron content and the fraction of zero-valent iron contained in the composite (Liu et al. 2005). For this, $0.1 \mathrm{~g}$ of sample was placed in a $10 \mathrm{~mL}$ glass vial and sealed with PTFE septa and an aluminum seal. $5 \mathrm{~mL}$ of hydrochloric acid (37\%) was added and allowed to react for $24 \mathrm{~h}$. Iron in the composite was consequently digested by the acid, which causes the reactive iron $\left(\mathrm{Fe}^{0}\right)$ to generate hydrogen gas by the following reaction (Eq. 2).

$$
2 \mathrm{Fe}^{0}+6 \mathrm{H}^{+} \rightarrow 2 \mathrm{Fe}^{3+}+3 \mathrm{H}_{2} \quad \text { (Eq. 2) }
$$

After 24 h, $0.2 \mathrm{~mL}$ of headspace gas was obtained using a precision syringe and the fraction of hydrogen in the gas was determined using gas chromatography (Mikrolab GC82, Mikrolab Aarhus A/S, Denmark). The column used was a $4.5 \mathrm{~m} \mathrm{x} 3.0 \mathrm{~mm}$ molecular sieve 5A column and nitrogen gas was used as the mobile phase. A thermal conductivity detector was used as the detector. The inlet, detector, and column temperatures were all adjusted to $90{ }^{\circ} \mathrm{C}$. The iron concentration of the liquid sample after acid digestion was analyzed by an atomic absorption spectrometer (AAS, AAnalyst 200, PerkinElmer, USA) to measure the total iron content. Based on the measured iron concentration and hydrogen gas concentration, the zero-valent iron content in the sample was determined. Briefly, measured hydrogen gas concentration (\%) was converted by calculation into hydrogen gas volume and hydrogen gas mole, and it further converted as mole of $\mathrm{Fe}(0)$ using the stoichiometric ratio given in Eq. 2. Finally, the calculated $\mathrm{Fe}(0)$ was compared with the measured total iron concentration by AAS to obtain the percentage of $\mathrm{Fe}(0)$ over total Fe.

\subsubsection{Scanning electron microscopy}

Scanning electron microscopy (FEI Inspect S, FEI, USA) was used to observe the microstructure and morphology of the synthesized samples. For smooth analysis of the sample, the surface of the sample was coated with gold using a sputter coater (Model 208HR, Cressington, UK).

\subsubsection{X-ray diffraction}

The chemical structure of GAC/Fe 2A was analyzed using X-ray diffraction (XRD) (D/MAX-RB, RIGAKU, Japan) 
analysis with $\mathrm{Cu} \mathrm{KN}$ radiation. The scan range of $2 \Theta$ was $30-80 \circ$ with a scan speed of $1 \% / \mathrm{min}$. Prior to measurement, the GAC/Fe 2A was ground to a powder by pestle and mortar and then applied for XRD analysis.

\subsection{Quantification of reducing reactivity of the GAC/Fe composites}

The reduction of nitrate to ammonium was used to determine the reduction reactivity of the synthesized sample. Reactivity testing was carried out using a $50 \mathrm{~mL}$ glass vial. $1 \mathrm{~g}$ of sample was added to the vial, $39 \mathrm{~mL}$ of acid solution was injected, and sealed with a PTFE septum and an aluminum seal. HEPES, acetic acid, hydrochloric acid, and citric acid were used as the acid solution and the concentration was $40 \mathrm{mM}$. Subsequently, $1 \mathrm{~mL}$ of nitrate stock solution was injected to initiate the reaction. Periodically, $2 \mathrm{~mL}$ of the sample was collected, filtered through a 0.45 $\mu \mathrm{m}$ filter; the filtrates were stored for eventual analysis. The initial concentration of nitrate in this test was set at $25 \mathrm{mg}$ $\mathrm{NO}_{3}-\mathrm{N} / \mathrm{L}$.

$$
4 \mathrm{Fe}^{0}+\mathrm{NO}_{3}{ }^{-}+7 \mathrm{H}_{2} \mathrm{O} \rightarrow 4 \mathrm{Fe}^{2+}+\mathrm{NH}_{4}^{+}+10 \mathrm{OH}^{-}(\text {Eq. 3) }
$$

Nitrate is reduced by zero-valent iron and converted into ammonium, as described in the above equation (Eq. 3), and the concentration of ammonium was measured using the colorimetric assay described in our previous research (Hwang et al. 2016). Ammonium was selected as the only measured product since the fate of nitrogen species during nitrate reduction by nZVI has already been reported in our previous research (Hwang et al. 2010; Hwang et al. 2011). It is necessary to evaluate the ammonium adsorption ability of the sample, since there is the possibility that the ammonium produced is adsorbed on the activated carbon and therefore not likely to be measured. That being said, an adsorption experiment using 25 mg-N/L of ammonium was carried out in the same manner as the above experiment using nitrate, and the amount of ammonium adsorbed over time was evaluated. Thus, the maximum amount of ammonium that can be produced is derived as the sum of the concentration of ammonium actually measured in the nitrate reduction experiment and the concentration of ammonium that can be removed by adsorption. The nitrate removal kinetics were simulated by the following first order reaction.

$$
\begin{gathered}
\mathrm{C}_{\mathrm{t}}=\mathrm{C}_{0} \times \mathrm{e}^{-\mathrm{kt}} \text { (Eq. 4) } \\
\left(\mathrm{C}_{\mathrm{t}}=\text { concentration at time } \mathrm{t}(\mathrm{mg} / \mathrm{L}), \mathrm{C}_{0}=\text { initial concentration }(\mathrm{mg} / \mathrm{L}), \mathrm{k}=\text { reaction kinetic constant }\left(\mathrm{min}^{-1}\right)\right)
\end{gathered}
$$

\section{RESULTS AND DISCUSSION}

\subsection{Effect of the GAC/Fe synthesis route on the production of $\mathrm{Fe}(0)$ in the composites}




\subsubsection{Optimization of GAC/Fe 2 and 3 synthesis routes}

In this study, the effect of synthesis conditions for GAC/Fe 2 and GAC/Fe 3 were evaluated and optimized. The synthesis condition for GAC/Fe 1 was not optimized in this study, as it was obtained from previous studies (Zhu et al. 2009). The optimization was to determine the best conditions for iron attachment, so the pH and iron concentration were chosen as experimental variables, and the effect of those variables on iron attachment was evaluated, illustrated in Fig. 2. The $\mathrm{pH}$ was varied from 3 (without $\mathrm{pH}$ adjustment) to 8 , and the $\mathrm{Fe}^{2+}$ concentration was varied from 10 to $100 \%$ of the applied GAC mass. The reaction time was set to be $24 \mathrm{~h}$ for all cases.

Fig 2. Total iron content in the GAC/Fe composites prepared in different $\mathrm{pH}$ and iron concentrations. Numbers in white boxes indicate the iron content (\%). Brown circles represent the experimental conditions conducted.

Higher iron content could be obtained when the $\mathrm{pH}$ and $\mathrm{Fe}^{2+}$ concentration were high. During the iron attachment process, the effect of $\mathrm{pH}$ on the morphology of $\mathrm{Fe}^{2+}$ solution could be clearly seen. A transparent $\mathrm{Fe}^{2+}$ solution was maintained in acidic conditions without $\mathrm{pH}$ adjustment, but the formation of iron precipitates were observed in neutral conditions, which might be due to the formation of iron hydroxides (Morgan and Hahav 2007). Therefore, we selected pH 3 and 7 as the two representative cases to investigate the effect of pH on the performance of composites. We named those as GAC/Fe $2(\mathrm{pH} \mathrm{3)}$ and GAC/Fe $3(\mathrm{pH} \mathrm{7).} \mathrm{It} \mathrm{was} \mathrm{hypothesized} \mathrm{that} \mathrm{GAC/Fe} 2$ has only chemical interactions such as electrostatic interaction between GAC surface and $\mathrm{Fe}^{2+}$ ions that create the attachment of iron ( $\mathrm{Fe}^{2+}$-GAC interaction/equilibrium), while GAC/Fe 3 will have physical iron precipitation on the GAC surface as well as the chemical interactions in GAC/Fe 2.

\subsubsection{Comparison of synthesis routes}

The observation of GAC/Fe 1 by scanning electron microscopy (SEM) is imaged in Fig. 3 (a-b). As observed in Fig. 3 (a), it can be seen that a thick layer is formed on the surface of the existing activated carbon particles. The thick layer is composed of the hexagonal plate-like structure as seen in Fig. 3 (b). In existing literature (Tseng et al. 2011), the state of iron after heat treatment was found to be present as $\alpha-\mathrm{Fe}_{2} \mathrm{O}_{3}$, and the hexagonal plate structure observed by SEM is a typical form of $\mathrm{Fe}_{2} \mathrm{O}_{3}$ (Fu et al. 2012).

Fig 3. SEM images of prepared GAC/Fe composites (a, b) GAC/Fe 1, (c, d) GAC/Fe 2, (e, f) GAC/Fe 3. 


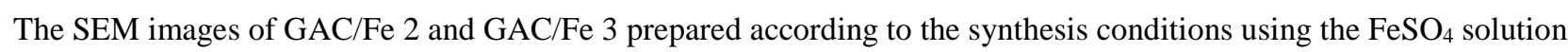
are observed in Fig. 3 (c-f). As seen in Fig. 3 (c) and (e), the pores of the activated carbon remained distinct, and no thick layer was formed on the surface. Moreover, as seen in Fig. 3 (d) and (f), it was confirmed that iron particles adhered to a part of the pores or the surface. In particular, it was confirmed that more iron particles were immobilized in the case of GAC/Fe 3, whose $\mathrm{pH}$ was adjusted to 7, compared to GAC/Fe 2, which did not have an adjusted pH.

The amount of attached iron was quantified by reactive iron analysis, as described in section 2.3.1; and it was presented in Fig 4. Fig. 4 plots the total iron content (w/w\%), the zero-valent iron content among attached iron (w/w\%), and the zero-valent iron content per gram of sample, respectively. In the case of GAC/Fe 1, the content of iron in the sample was $16.7 \%$, which was considerably high. However, the ratio of zero-valent iron was very low, $0.16 \%$, and the content of zero-valent iron per g of sample was only $0.27 \mathrm{mg} / \mathrm{g}$. These results indicate that the iron deposition process for GAC/Fe 1 can physically deposit a large amount of iron using a high concentration of iron solution, but most of the iron deposited using these conditions exists in the form of iron oxide $\left(\alpha-\mathrm{Fe}_{2} \mathrm{O}_{3}\right)$, which is hard to reduce to elemental iron. This is consistent with the results of previous studies in which reduction of iron oxide ( $\alpha$ $\mathrm{Fe}_{2} \mathrm{O}_{3}$ ) by $\mathrm{NaBH}_{4}$ occurs mostly on the surface and overall efficiency is low (de Resende et al. 2007). Recently, a study by Bae et al. (Bae et al. 2016) have reported that the iron reactivity with $\mathrm{NaBH}_{4}$ varies greatly depending on the type of iron oxide. Therefore, it is necessary to control the synthesis conditions of iron oxide to increase the conversion of said iron oxides to zero-valent iron.

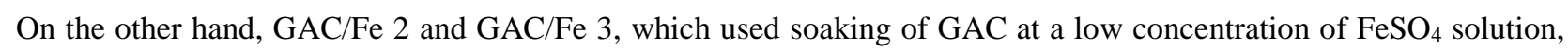
had significantly different results compared to GAC/Fe 1. Total iron contents were significantly lower than GAC/Fe 1, 1.03\% and 2.71\% for GAC/Fe 2 and GAC/Fe 3, respectively. GAC/Fe 3 exhibited a higher total iron content, owing to the $\mathrm{pH}$ adjustment leading to iron hydroxide precipitates being formed. These results agreed well with the obtained SEM images. The ratios of zero-valent iron were much higher than that of GAC/Fe 1, 11.0\% and 4.1\% for GAC/Fe 2 and GAC/Fe 3. Finally, the zero-valent iron content in the composites was calculated to be 1.14 and $1.10 \mathrm{mg} / \mathrm{g}$ composite for GAC/Fe 2 and GAC/Fe 3, respectively. These results clearly explained that the form of iron attached was one of the most important factors in determining the overall performance of the GAC/Fe composite, and it is important to control the synthesis conditions when preparing a reactive GAC/Fe composite.

Fig 4. Total iron and zero-valent iron content in the composites prepared using different synthesis routes. 


\subsubsection{One-pot synthesis}

Based on the results in section 3.1.2, we have tested a one-pot synthesis regime for GAC/Fe 2 and GAC/Fe 3 samples. Previously, GAC was immersed in $\mathrm{Fe}^{2+}$ solution, washed with deionized water and ethanol, dried in a vacuum oven for $4 \mathrm{~h}$, and finally reduced to nZVI form using $\mathrm{NaBH}_{4}$ solution. For the one-pot synthesis regime, GAC was immersed in a $\mathrm{Fe}^{2+}$ solution, and then the $\mathrm{Fe}^{2+}$ solution was removed using a sieve and the reduction by $\mathrm{NaBH}_{4}$ solution was conducted without an intermediate drying step. The prepared samples in the one-pot synthesis regime were named as GAC/Fe 2A and GAC/Fe 3A.

Table 1. Total iron and zero-valent iron content in the composites prepared by the one-pot synthesis scheme.

The total iron content and the zero-valent iron content of the synthesized GAC/Fe 2A and GAC/Fe 3A were measured and compared with the previous samples. The total iron contents were $1.69 \%$ and $3.20 \%$ for GAC/Fe $2 \mathrm{~A}$ and GAC/Fe 3A, respectively, which were higher than in previous samples. This indicates that the iron that has been physically attached to the surface can be washed away by several washes of deionized water and ethanol. The fraction of zerovalent iron was $78.6 \%$ in the case of GAC/ Fe 2A, which was 4.1 times higher than that of the general sample, indicating that there was $13.3 \mathrm{mg}$ of zero-valent iron per g of sample. GAC/Fe 3A also showed 4.8 times higher zerovalent iron content than that of the general sample, indicating the advantage of the one-pot synthesis.

The high content of zero-valent iron confirmed that the $\mathrm{Fe}^{2+}$ attached could be converted to iron oxide or iron hydroxide during the drying step, which is difficult to reduce using $\mathrm{NaBH}_{4}$. In order to obtain high iron and zerovalent iron content, it is important to omit the intermediate washing and drying entirely. Therefore, the optimal condition was determined to be GAC/Fe 2A, which uses $\mathrm{FeSO}_{4}$ solution as a precursor and then reduces it to $\mathrm{Fe}(0)$ without any $\mathrm{pH}$ adjustment or intermediate washing and drying step.

The XRD analysis was conducted for GAC/Fe 2A, in order to confirm the chemical composition of the iron product. As illustrated in Fig. 5, the weak peak of zero-valent iron located at a $2 \theta$ of $44.9^{\circ}$ was identified. At the same time, a minor peak of magnetite, one of the iron corrosion product, was also identified at a $2 \theta$ of $35.8^{\circ}$. This result indicated that the iron product immobilized on the GAC/Fe 2A sample is mostly zero-valent iron, with a minor amount of iron oxide. This result is well agreed with the reactive iron content analysis using acid digestion followed by $\mathrm{H}_{2}$ generation, 
which is an effective and versatile method for determining optimal synthesis conditions in this study.

\section{Fig 5. XRD spectra of GAC/Fe 2A}

We calculated the iron mass balance in the one-pot synthesis for GAC/Fe 2A. Initially, $7 \mathrm{~g}$ of $\mathrm{Fe}^{2+}$ was applied for 10 g of GAC. Solid-liquid separation was done using a sieve, then the collected solid was subsequently used for reduction to zero-valent iron. The iron content, determined by atomic absorption, in the liquid fraction was determined to be $6.6 \mathrm{~g}$ of Fe, which means only $5.7 \%$ of the iron was attached by immersion of GAC. Therefore, the remaining solution still contains very high concentration of $\mathrm{Fe}^{2+}$, which yields the possibility of recycling the solutions used. Among the attached iron, $60 \%$ was lost during the final washing step; consequently, $1.7 \%$ of iron content could be achieved.

\subsection{Reducing reactivity of prepared GAC/Fe composites}

\subsubsection{Nitrate reduction in various acid solutions}

Fig 6. (a) Produced ammonium profiles under different acid conditions, (b) pH variation during the reaction, (c) positive control to confirm validity of colorimetric assay.

The prepared GAC/Fe 2A composite was applied for nitrate reduction in various acid conditions, as plotted in Fig. 6(a). An almost negligible production of ammonium was obtained without applying any buffer to the system. This is due to an increased $\mathrm{pH}$, to above 9.5, by the production of hydroxyl ions as a byproduct of the nitrate reduction and reaction with water (Eq. 3) (Hwang et al. 2011).

The high pH causes a formation of an iron oxide layer on the surface of nZVI, which inhibits electron transfer for nitrate reduction. This is well agreed with previous literatures studying the effect of $\mathrm{pH}$ on nitrate reduction (Hwang et al. 2010; Bae and Hanna 2015). In order to overcome this pH issue, we have tested several common acids to provide acidity in solution, those being HEPES, acetic acid, hydrochloric acid, and citric acid. The concentration of each acid was set to be $40 \mathrm{mM}$, which is enough for consuming all the hydroxyl ions produced (35.8 mM) during the reaction of the $\mathrm{Fe}(0)$ added $(17.9 \mathrm{mM})$. 
Addition of acid was helpful to maintain $\mathrm{pH}$ in a certain region (Fig 6(b)). Each acid has a different pH region, for example, HEPES maintained a pH of around 7, while a pH of 3-4 was maintained by citric acid. The ammonium generation profiles was significantly affected by the acid used. Depending on the acid used, different reaction kinetics and capacities were obtained. Among the four acids tested, acetic acid was determined to be the most desirable acid, in terms of reactivity. The $\mathrm{pH}$ was maintained in the range of 4 to 6 .

The produced ammonium concentrations were obtained by the colorimetric assay using a microplate described in our previous study (Hwang et al. 2016). In order to verify the effectiveness of the color assay, a positive control test was conducted. A known amount of ammonium was added to the samples and checked for differences in absorbance. This test was conducted to make sure that the colorimetric assay was not altered by the solution conditions, such as pH or any other acid species. As plotted in Fig 6 (c), the addition of $0.4 \mathrm{mg} / \mathrm{L}$ of ammonium caused an increase in the absorbance, of around 0.31 , which was almost identical for all the test conditions.

\subsubsection{Validation of multi-well microplate based colorimetric assay for quantification of reaction products through nitrogen mass balance}

The possibility of applying GAC/Fe 2A to the pollutant removal process was evaluated using nitrate as a model pollutant. It was known that nitrate is converted into ammonium through the reaction with zero-valent iron; therefore, the concentration of the reaction product ammonium was monitored to assess the reduction reaction. The initial concentration of nitrate as nitrogen $\left(\mathrm{NO}_{3}-\mathrm{N}\right)$ was set at $25 \mathrm{mg}-\mathrm{N} / \mathrm{L}$. The initial $\mathrm{pH}$ of the solution was 4.0, due to the addition of acetic acid as a buffer. After $4 \mathrm{~h}$ of reaction, the $\mathrm{pH}$ rose to 6.0, indicating that the entire reaction proceeded under acidic conditions.

\section{Fig 7. Nitrogen mass balance during nitrate reduction by GAC/Fe 2A.}

The concentration of ammonium increased rapidly, up to $11.8 \mathrm{mg}-\mathrm{N} / \mathrm{L}$ during the initial 60 min, then slightly decreased to $11.6 \mathrm{mg}-\mathrm{N} / \mathrm{L}$ at a reaction time of $4 \mathrm{~h}$. These results indicated that the GAC/Fe 2A can reduce the nitrate to ammonium, as well as adsorb the generated ammonium. Therefore, it was not possible to measure the maximum amount of ammonium produced simply by monitoring the concentration of ammonium. In order to overcome these limitations, the ammonium adsorption experiment of the GAC/Fe 2A was carried out simultaneously. The initial ammonium concentration was $25 \mathrm{mg}-\mathrm{N} / \mathrm{L}$, and it decreased to $12.8 \mathrm{mg}-\mathrm{N} / \mathrm{L}$ at $4 \mathrm{~h}$ of reaction time. In order to obtain 
the maximum removal rate of nitrate, while also considering the adsorption of ammonium, the sum of the amount of ammonium produced and the amount of adsorbed ammonium was set as the maximum removal of nitrate.

The nitrate removal efficiency increased with respect to time, and it was almost unchanged after $1 \mathrm{~h}$ of reaction time. At this time, the total removed nitrate was calculated to be $23.9 \mathrm{mg}-\mathrm{N} / \mathrm{L}$, which was $95.6 \%$ when compared with the initial concentration of 25 mg-N/L. The overall nitrogen reduction kinetics were calculated through a pseudo-firstorder reaction and the kinetics constant was found to be $\mathrm{k}=0.0519 \mathrm{~min}^{-1}$.

\section{Conclusion}

Throughout this study, we compared the nZVI immobilization process using GAC as the supporting media, in terms of iron loading and its reactivity. In order to synthesize an effective GAC/Fe composite, it is important to increase the fraction of zero-valent iron while still maintaining a high iron content; furthermore, it is important to inhibit the formation of iron oxides and iron hydroxides during the synthesis process. The optimum conditions were determined to be immersing GAC in a $\mathrm{Fe}^{2+} 0.84 \mathrm{M}$ solution without any $\mathrm{pH}$ adjustment for $24 \mathrm{~h}$, and then reducing it for $2 \mathrm{~h}$ in a 1.19 $\mathrm{M} \mathrm{NaBH}_{4}$ solution without an intermediate drying step, therefore labelled a one-pot synthesis. The prepared GAC/Fe 2A was effective for the removal of water contaminants, such as nitrate, and possesses both the adsorption capacity of activated carbon and the reducing ability of zero-valent iron. The reducing reactivity of prepared GAC/nZVI was successfully investigated and compared with the colorimetric assay for determining nZVI reactivity developed in our previous study.

\section{Acknowledgement}

This study was supported by the Underground environmental pollution risk management technology development program funded by the Ministry of Environment in the Republic of Korea (2018002480004).

\section{Conflict of interest}

On behalf of all authors, the corresponding author states that there is no conflict of interest.

\section{Reference}

Bae S, Gim S, Kim H, Hanna K (2016) Effect of NaBH4 on properties of nanoscale zero-valent iron and its catalytic activity for reduction of p-nitrophenol. Appl Catal B Environ 182:541-549. doi: 
https://doi.org/10.1016/j.apcatb.2015.10.006

Bae S, Hanna K (2015) Reactivity of Nanoscale Zero-Valent Iron in Unbuffered Systems: Effect of pH and Fe(II) Dissolution. Environ Sci Technol 49:10536-10543. doi: 10.1021/acs.est.5b01298

Choi H, Al-Abed SR, Agarwal S, Dionysiou DD (2008) Synthesis of Reactive Nano-Fe/Pd Bimetallic SystemImpregnated Activated Carbon for the Simultaneous Adsorption and Dechlorination of PCBs. Chem Mater 20:3649-3655. doi: 10.1021/cm8003613

Crane RA, Scott TB (2012) Nanoscale zero-valent iron: Future prospects for an emerging water treatment technology. J Hazard Mater 211-212:112-125. doi: 10.1016/j.jhazmat.2011.11.073

de Resende VG, De Grave E, da Costa GM, Janssens J (2007) Influence of the borohydride concentration on the composition of the amorphous Fe-B alloy produced by chemical reduction of synthetic, nano-sized iron-oxide particles: Part I: Hematite. J Alloys Compd 440:236-247. doi: 10.1016/j.jallcom.2006.09.040

Fu L-S, Jiang J-T, Xu C-Y, Zhen L (2012) Synthesis of hexagonal Fe microflakes with excellent microwave absorption performance. CrystEngComm 14:6827-6832. doi: 10.1039/C2CE25836F

Grover DP, Zhou JL, Frickers PE, Readman JW (2011) Improved removal of estrogenic and pharmaceutical compounds in sewage effluent by full scale granular activated carbon: Impact on receiving river water. J Hazard Mater 185:1005-1011. doi: https://doi.org/10.1016/j.jhazmat.2010.10.005

Hameed BH, Salman JM, Ahmad AL (2009) Adsorption isotherm and kinetic modeling of 2,4-D pesticide on activated carbon derived from date stones. J Hazard Mater 163:121-126. doi: https://doi.org/10.1016/j.jhazmat.2008.06.069

Hwang Y-H, Kim D-G, Shin H-S (2011) Mechanism study of nitrate reduction by nano zero valent iron. J Hazard Mater 185:. doi: 10.1016/j.jhazmat.2010.10.078

Hwang Y, Lee Y-C, Mines PD, Huh YS, Andersen HR (2014) Nanoscale zero-valent iron (nZVI) synthesis in a Mgaminoclay solution exhibits increased stability and reactivity for reductive decontamination. Appl Catal B Environ 147:748-755. doi: 10.1016/j.apcatb.2013.10.017

Hwang Y, Salatas A, Mines PD, Jakobsen MH, Andersen HR (2016) Graduated characterization method using a multiwell microplate for reducing reactivity of nanoscale zero valent iron materials. Appl Catal B Environ 181:314320. doi: 10.1016/j.apcatb.2015.07.041

Hwang YH, Kim DG, Ahn YT, Moon CM, Shin HS (2010) Fate of nitrogen species in nitrate reduction by nanoscale zero valent iron and characterization of the reaction kinetics. Water Sci Technol 61:705-712. doi: 10.2166/wst.2010.895

Kim H, Hong H-J, Jung J, Kim S-H, Yang J-W (2010) Degradation of trichloroethylene (TCE) by nanoscale zero-valent 
iron (nZVI) immobilized in alginate bead. J Hazard Mater 176:1038-1043. doi: 10.1016/j.jhazmat.2009.11.145

Kobya M, Demirbas E, Senturk E, Ince M (2005) Adsorption of heavy metal ions from aqueous solutions by activated carbon prepared from apricot stone. Bioresour Technol 96:1518-1521. doi: https://doi.org/10.1016/j.biortech.2004.12.005

Liu C, Li X, Ma B, Qin A, He C (2014) Removal of water contaminants by nanoscale zero-valent iron immobilized in PAN-based oxidized membrane. Appl Surf Sci 321:158-165. doi: 10.1016/j.apsusc.2014.09.202

Liu Y, Majetich SA, Tilton RD, Sholl DS, Lowry G V (2005) TCE Dechlorination Rates, Pathways, and Efficiency of Nanoscale Iron Particles with Different Properties. Environ Sci Technol 39:1338-1345. doi: 10.1021/es049195r

Mines PD, Thirion D, Uthuppu B, Hwang Y, Jakobsen MH, Andersen HR, Yavuz CT (2017) Covalent organic polymer functionalization of activated carbon surfaces through acyl chloride for environmental clean-up. Chem Eng J 309:. doi: 10.1016/j.cej.2016.10.085

Mines PD, Uthuppu B, Thirion D, Jakobsen MH, Yavuz CT, Andersen HR, Hwang Y (2018) Granular activated carbon with grafted nanoporous polymer enhances nanoscale zero-valent iron impregnation and water contaminant removal. Chem Eng J accepted: doi: 10.1016/j.cej.2018.01.102

Morgan B., Lahav O (2007) The effect of pH on the kinetics of spontaneous Fe(II) oxidation by O2 in aqueous solution - basic principles and a simple heuristic description. Chemosphere 68:2080-2084.

Rivera-Utrilla J, Sánchez-Polo M, Gómez-Serrano V, Álvarez PM, Alvim-Ferraz MCM, Dias JM (2011) Activated carbon modifications to enhance its water treatment applications. An overview. J Hazard Mater 187:1-23. doi: https://doi.org/10.1016/j.jhazmat.2011.01.033

Savage N, Diallo MS (2005) Nanomaterials and Water Purification: Opportunities and Challenges. J Nanoparticle Res 7:331-342. doi: 10.1007/s11051-005-7523-5

Subramani AK, Byrappa K, Ananda S, Lokanatha Rai KM, Ranganathaiah C, Yoshimura M (2007) Photocatalytic degradation of indigo carmine dye using TiO2 impregnated activated carbon. Bull Mater Sci 30:37-41. doi: $10.1007 / \mathrm{s} 12034-007-0007-8$

Tang CY, Zhao Y, Wang R, Hélix-Nielsen C, Fane AG (2013) Desalination by biomimetic aquaporin membranes: Review of status and prospects. Desalination 308:34-40. doi: https://doi.org/10.1016/j.desal.2012.07.007

Tseng H-H, Su J-G, Liang C (2011) Synthesis of granular activated carbon/zero valent iron composites for simultaneous adsorption/dechlorination of trichloroethylene. J Hazard Mater 192:500-506. doi: 10.1016/j.jhazmat.2011.05.047

Yoon KY, Byeon JH, Park CW, Hwang J (2008) Antimicrobial Effect of Silver Particles on Bacterial Contamination of Activated Carbon Fibers. Environ Sci Technol 42:1251-1255. doi: 10.1021/es0720199 
Zhu H, Jia Y, Wu X, Wang H (2009) Removal of arsenic from water by supported nano zero-valent iron on activated carbon. J Hazard Mater 172:1591-1596. doi: 10.1016/j.jhazmat.2009.08.031 
Table 1 Total iron and zero-valent iron content in the composites prepared by the one-pot synthesis scheme.

\begin{tabular}{cccc}
\hline & Total Fe (\%) & $\mathrm{Fe}^{\circ}(\%)$ & $\begin{array}{c}\text { Available Fe } \\
(\mathrm{mg} \mathrm{Fe/g} \mathrm{GAC})\end{array}$ \\
\hline GAC 2 & 1.03 & 11.0 & 1.14 \\
GAC 2A & 1.69 & 78.6 & 13.3 \\
\hline GAC 3 & 2.71 & 4.1 & 1.10 \\
\hline GAC 3A & 3.20 & 19.7 & 6.3 \\
\hline
\end{tabular}




\section{Figure captions}

Fig 1. Overall synthesis procedures for the different GAC/Fe composites.

Fig 2. Total iron content in the GAC/Fe composites prepared in different $\mathrm{pH}$ and iron concentrations. Numbers in white boxes indicate the iron content (\%). Brown circles represent the experimental conditions conducted.

Fig 3. SEM images of prepared GAC/Fe composites (a, b) GAC/Fe 1, (c, d) GAC/Fe 2, (e, f) $\mathrm{GAC} / \mathrm{Fe} 3$

Fig 4. Total iron and zero-valent iron content in the composites prepared using different synthesis routes.

Fig 5. XRD spectra of GAC/Fe 2A

Fig 6. (a) Produced ammonium profiles under different acid conditions, (b) $\mathrm{pH}$ variation during the reaction, (c) positive control to confirm validity of colorimetric assay.

Fig 7. Nitrogen mass balance during nitrate reduction by GAC/Fe 2A. 


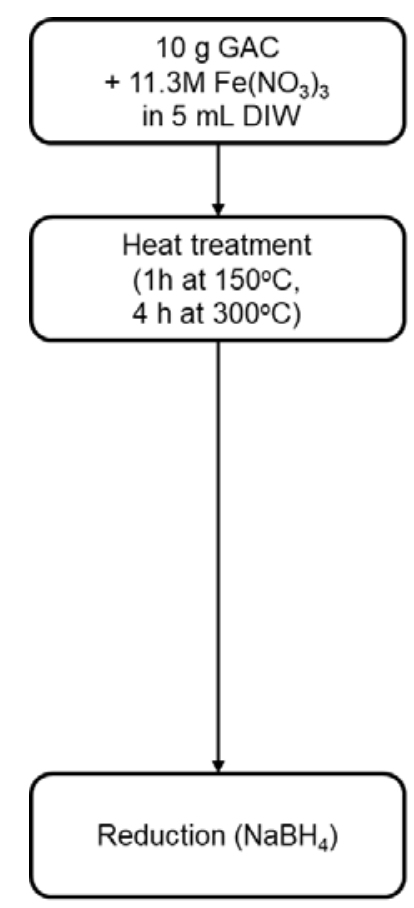

GAC/Fe 1

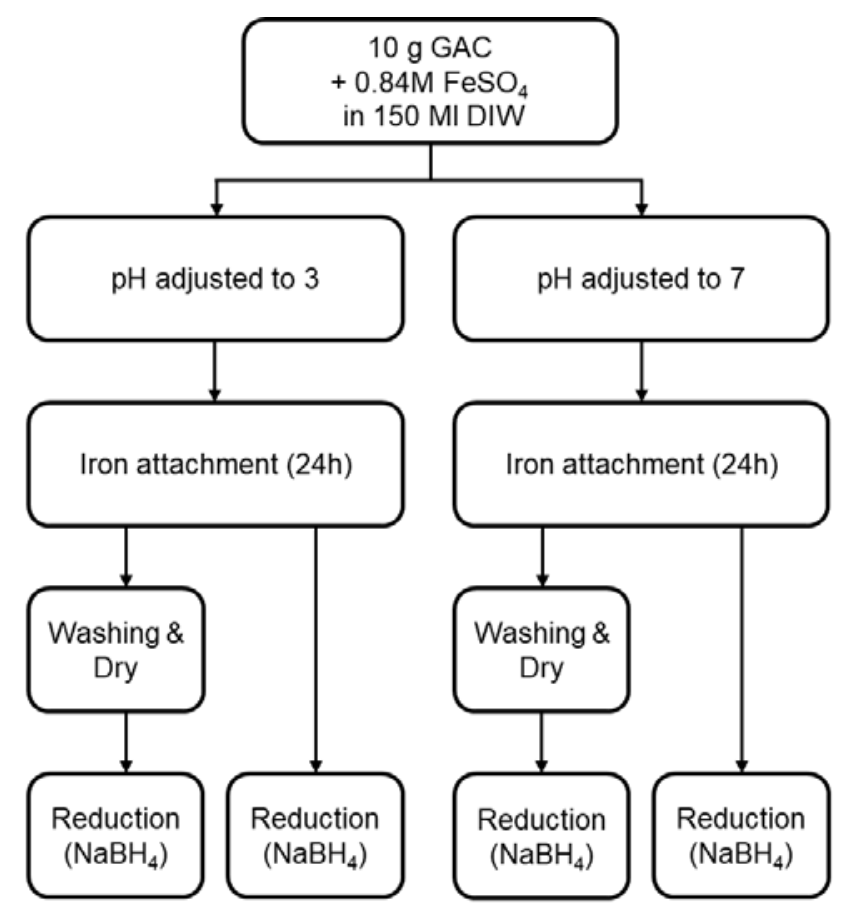

GAC/Fe 2 GAC/Fe 2A GAC/Fe 3 GAC/Fe 3A

Fig 1. Overall synthesis procedures for the different GAC/Fe composites. 


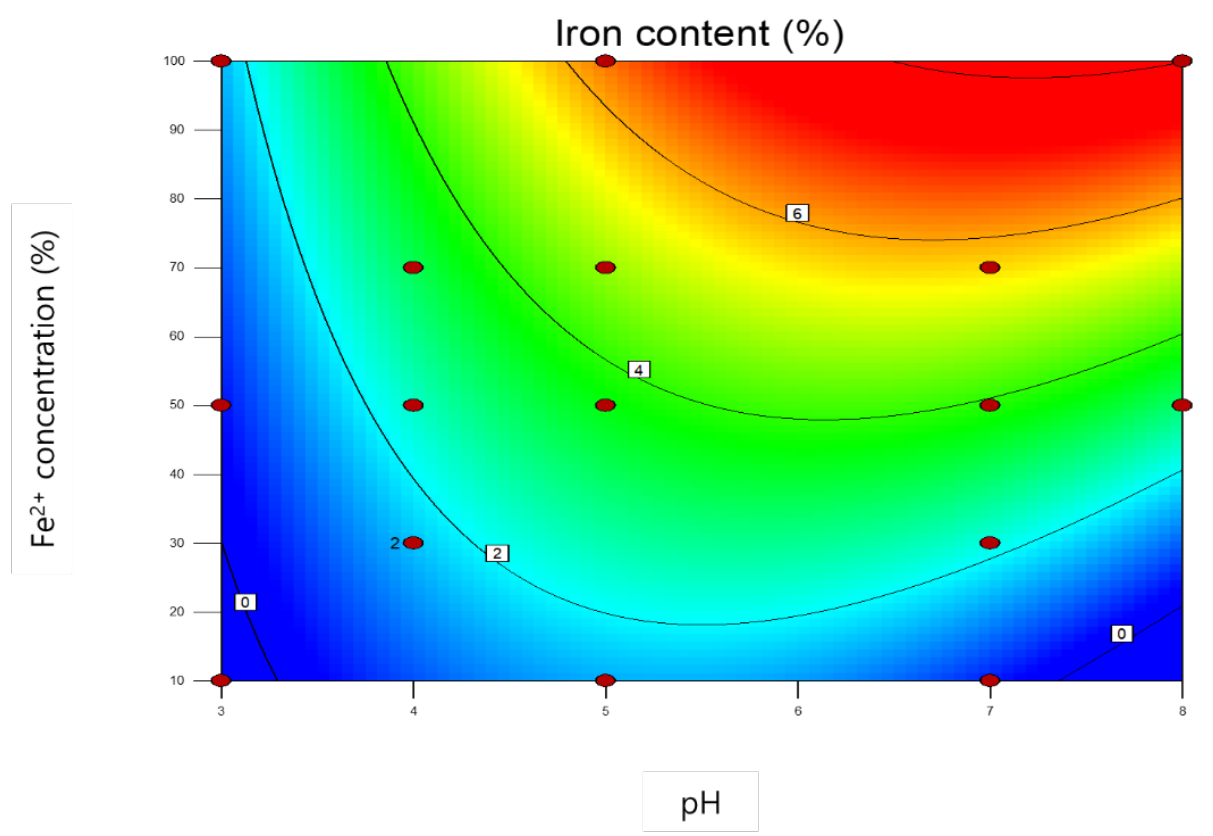

Fig 2. Total iron content in the GAC/Fe composites prepared in different $\mathrm{pH}$ and iron concentrations. Numbers in white boxes indicate the iron content (\%). Brown circles represent the experimental conditions conducted.

(a

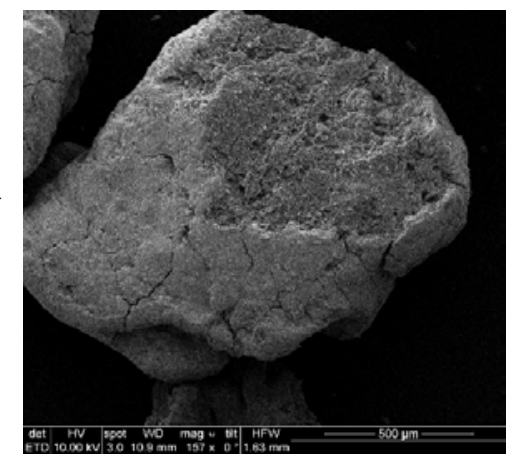

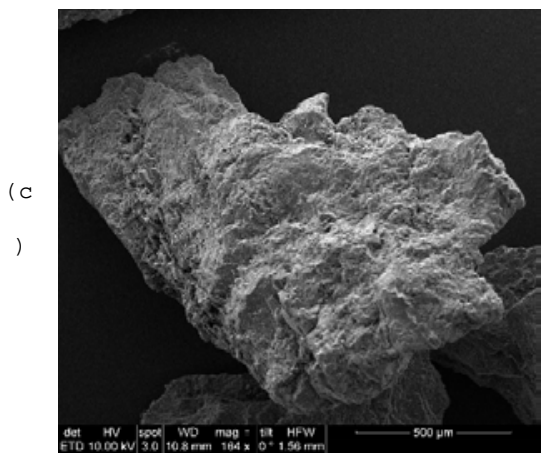

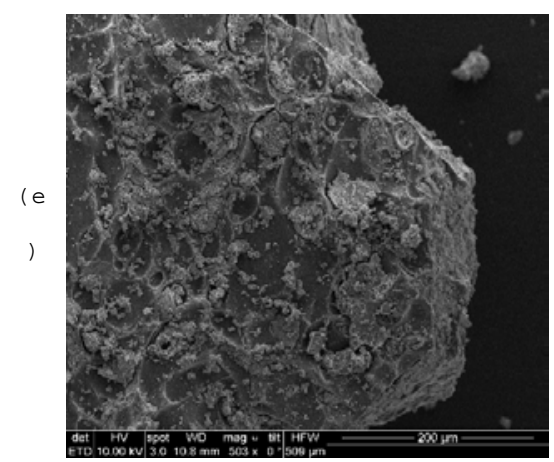



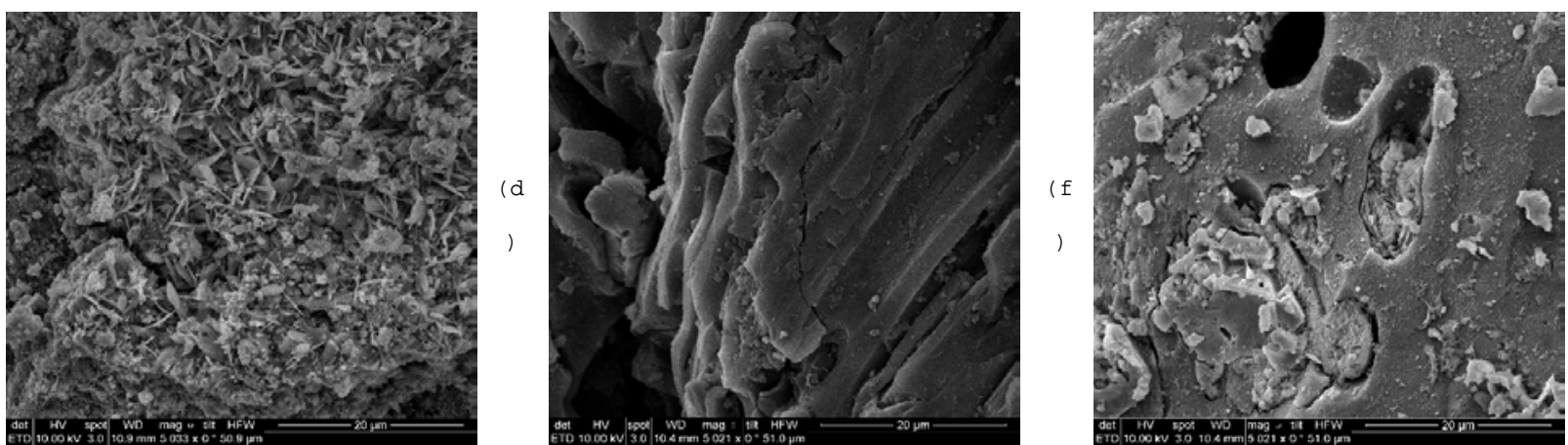

Fig 3. SEM images of prepared GAC/Fe composites (a, b) GAC/Fe 1, (c, d) GAC/Fe 2, (e, f) GAC/Fe 3.

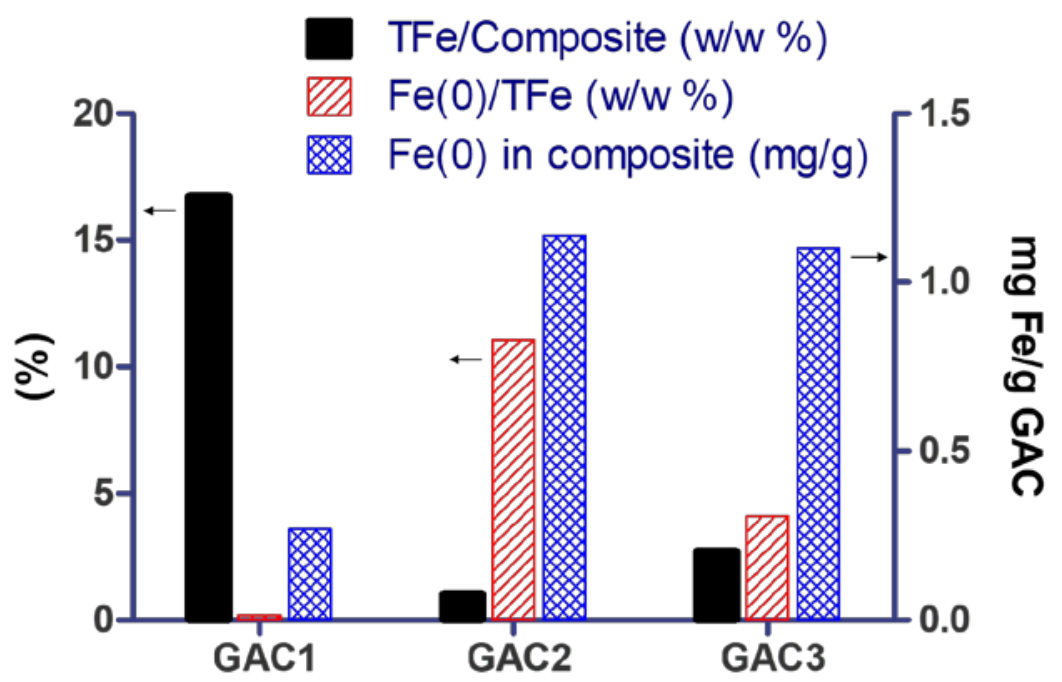

Fig 4. Total iron and zero-valent iron content in the composites prepared using different synthesis routes. 


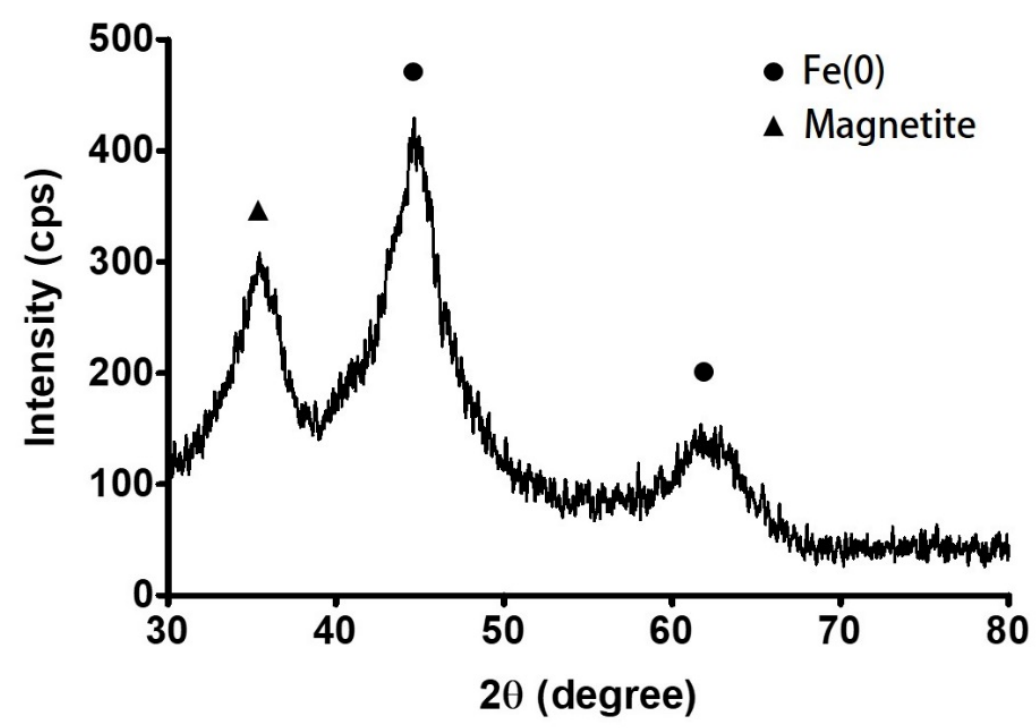

Fig 5. XRD spectra of GAC/Fe 2A 


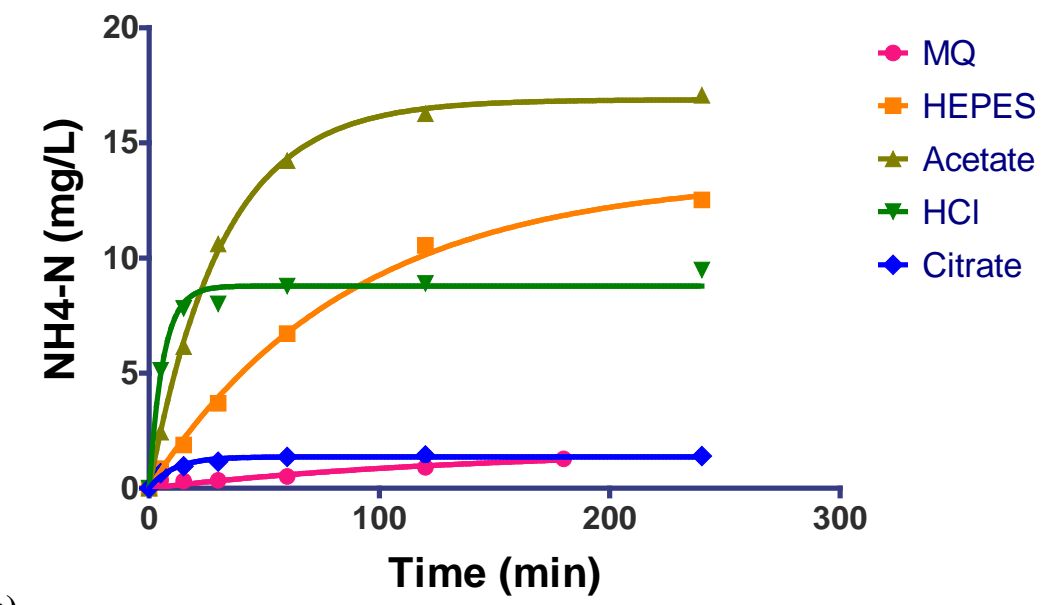

(a)

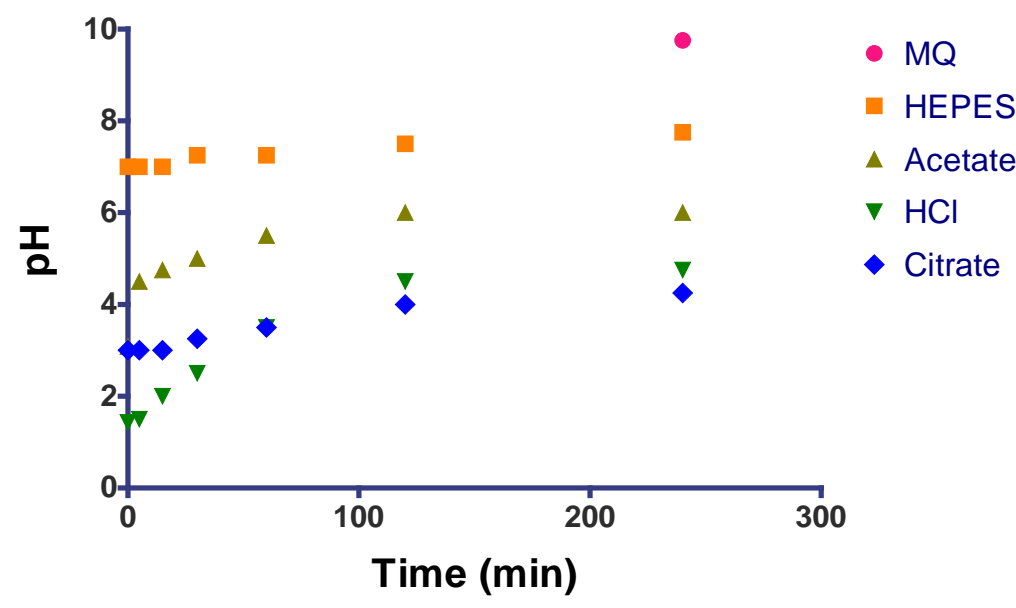

(b)

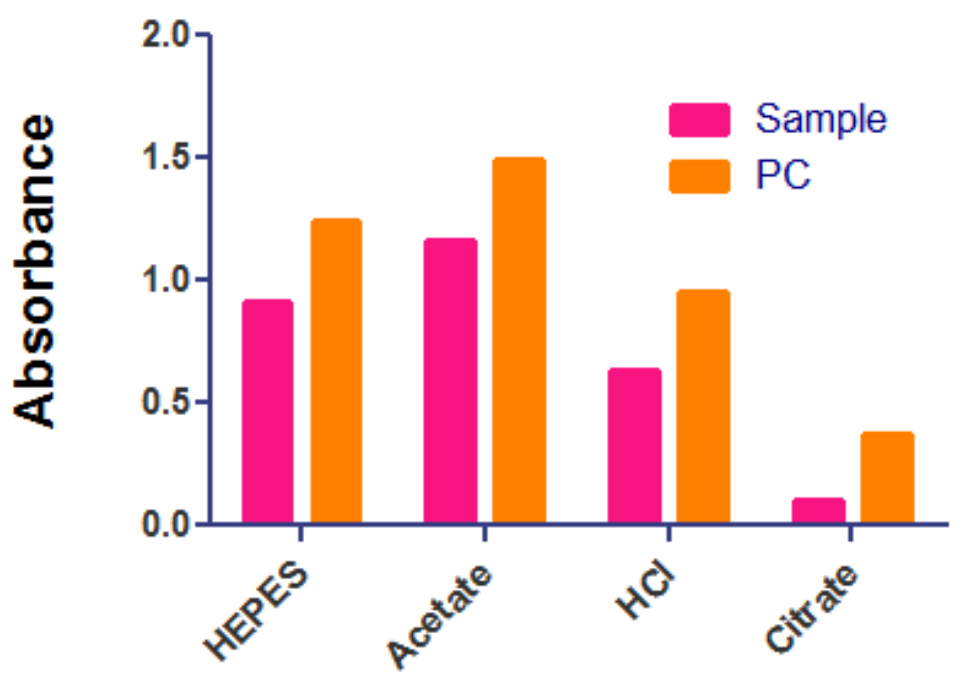

Fig 6. (a) Produced ammonium profiles under different acid conditions, (b) $\mathrm{pH}$ variation during the reaction, (c) positive control to confirm validity of colorimetric assay. 


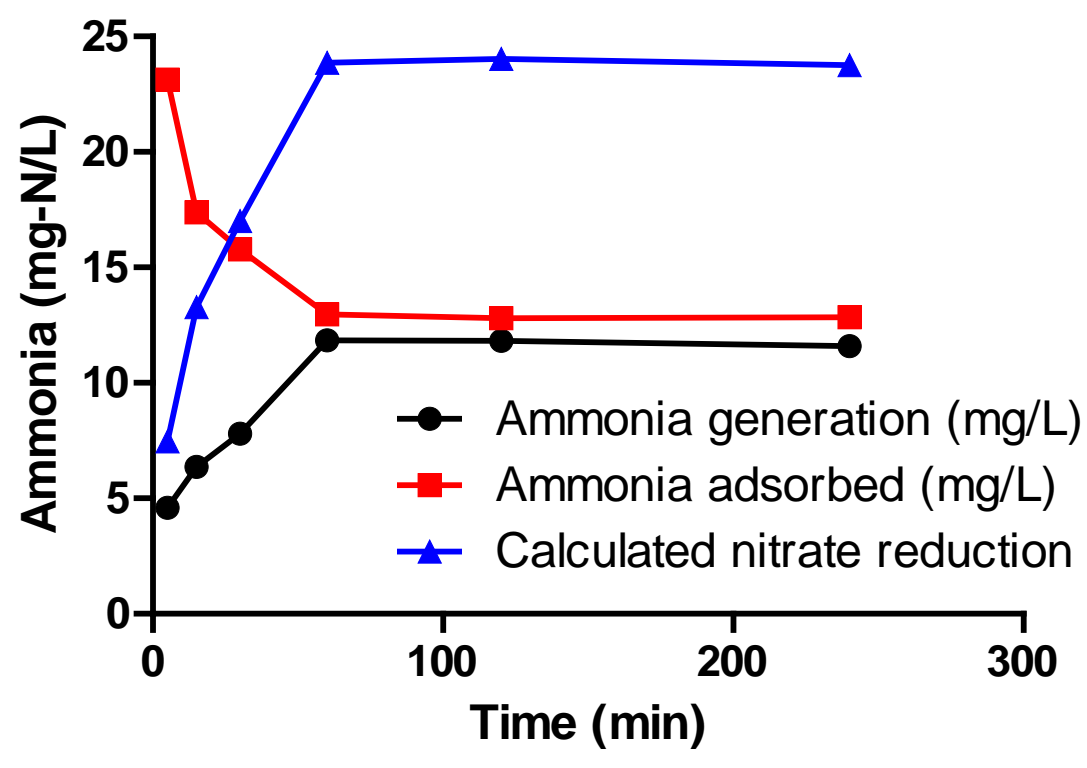

Fig 7. Nitrogen mass balance during nitrate reduction by GAC/Fe $2 \mathrm{~A}$. 